\title{
Las murallas urbanas
}

\author{
Vicente Salvatierra Cuenca*
}

\section{INTRODUCCIÓN}

La muralla bajomedieval de Jaén empieza y termina en los alcázares ubicados en la cima del Cerro de Sta Catalina, incluyendo en su recorrido la ciudad. En base a esto puede considerarse dividida en tres tramos. Las murallas Norte y Sureste, que ocupan el espacio entre los alcázares y las puertas de Martos y Granada respectivamente. Y la muralla urbana, que se extiende entre las dos puertas. A ella hay que añadir las murallas de los arrabales.

El presente texto se refiere a la muralla Urbana y a las construidas posteriormente para cerrar los arrabales. En cierto sentido es una puesta al día de los datos ya conocidos, pero empleando dos fuentes hasta ahora no utilizadas. En primer lugar se ha prestado una atención especial, para gran parte del recorrido de la cerca, al dibujo que Antón Van den Wyngaerde, pintor al servicio de Felipe II, realizó en I567, obra que estimamos insustituible para aclarar varias de las polémicas o de las dudas que las noticias escrita proporcionan. En segundo lugar, se han añadido los datos provenientes de un elevado número de excavaciones efectuadas en los últimos años, lo que ha permitido no sólo agregar más precisiones, sino efectuar nuevas lecturas de las informaciones de los textos y rectificar cierto número de apreciaciones acerca del recorrido.
El estudio procura recoger todos los elementos (torres, puertas, portillos, etc.) de que constaba la muralla, relacionando las tres fuentes (escritas, arqueológicas y dibujo). Aunque como en su momento indicó $\mathrm{M}^{\mathrm{a}} \mathrm{S}$. Lázaro (1988) muchos de ellos se añadieron a lo largo de tiempo, y por tanto no pueden considerarse medievales, para facilitar la descripción hemos efectuado una descripción lineal, aunque indicando la cronología de los elementos cuando esta era conocida.

Fue también $M^{a} S$. Lázaro prácticamente la primera autora contemporánea que hizo referencia a la complejidad transversal -o en profundidad- de las defensas, pese a la importancia de las mismas. En este aspecto, además de los documentos de las Actas capitulares de Jaén empleados por dicha autora, hemos incluido los detalles que sobre este aspecto están contenidos en algunas crónicas medievales. En la Crónica de la población de Ávila, se relata la participación de caballeros de dicha localidad en los tres cercos de Jaén, aunque la misma sólo menciona las barreras que protegían la ciudad. Por su parte la versión editada por Florian de Ocampo de la Crónica General es más explícita, ya que al hablar del cerco de 1225 señala que: "allanaron las cauas que eran fondas e furacaron las barbacanas e hirianse los caballeros a manteniente dentro de la barbacana...". Es decir,

* Universidad de Jaén 
había fosos y antemuros delante de la muralla propiamente dicha. Por último, en el último cuarto del siglo XV la Relación de los hechos de... D. Miguel Lucas... Condestable de Castilla describe algunas de las defensas de la ciudad, y las obras realizadas por este. Entre ellas se citan nuevos fosos (cavas) y muros (tapias) construidos en 1465, levantados por delante de las murallas de la ciudad, a los que haremos referencia en cada caso. Finalmente, esa complejidad, ha sido puesta recientemente de manifiesto por algunas excavaciones arqueológicas.

\section{LA MURALLA DE LA MAGDALENA O DE LA CARRETERA DE CÓRDOBA}

Denominamos así al tramo que va desde la Puerta de Martos hasta la del Aceituno, constituyendo el límite de la población por el Norte, aprovechando los quiebros de la roca, que aflo$\mathrm{ra}$ en algunos tramos.

La Puerta de Martos permaneció en pie hasta 1865 , lo que ha posibilitado que aún nos hayan llegado imágenes de ella (CAZABAN 1930a) y que hayan podido hacerse intentos de reconstrucción de su aspecto relativamente bien fundamentados (ESLAVA 1999:63), aunque las excavaciones recientes han permitido establecer realmente su estructura y evolución (BARBA et alii 2004). Ocupaba, según el dibujo de Anton Van den Wyngaerde, el extremo Noroeste del recinto, de donde partía el camino a Martos, del que tomó el nombre la Puerta. La calle que se dirigía a esta era conocida entre los siglos $\mathrm{XV}$ y $\mathrm{XVI}$ precisamente por esa circunstancia (Calle que va a la Puerta de Martos), y a partir del siglo XVIII aparece en la documentación como Puerta de Martos. El derribo de la Puerta hizo que entre finales del siglo XIX y primera mitad del XX, la calle fue designada indistintamente como Pta de Martos o Magdalena Baja. En los años 50, la reorganización y urbanización de la zona consolidará hasta el presente el nombre de la Puerta para los tramos más próximos a la zona donde aquella había estado.

El recinto urbano se estrechaba considerablemente a partir de la Puerta de Martos, de forma que vista desde el Norte esta quedaba en el extremo de un espolón.

Según Ma S. Lázaro (1988:31): "Tras rebasar la puerta de Martos y franquear un barranco' la muralla se deslizaba en dirección N-NE, hasta enlazar con la actual Carretera de Córdoba por su margen superior".

En esta interpretación parece haber un error de localización de la Puerta o de interpretación de la topografía, ya que el lado Norte de la puerta se sitúa precisamente en la manzana que separa la actual Calle de la Puerta de Martos de la Carretera de Circunvalación. El espacio no es excesivo, ya que se circunscribe a salvar parte del desnivel existente entre la calle y la carretera. El barranco mencionado, difícil de interpretar en este contexto, pudo ser desde un resto del foso situado por delante de la muralla a que hace alusión el Condestable Iranzo, hasta una vaguada que cortase transversalmente la zona.

En cualquier caso, como dibujó J. Eslava (1999) y han confirmado las excavaciones, la muralla formaba en la práctica el lateral Norte de la Puerta y desde ella seguía en dirección Este, por el interior de la larga y ondulante manzana que caracteriza la zona, formada precisamente por el adosamiento de viviendas a un lado y otro de la misma. De esta manera, la presencia de la muralla contribuyó a generar la orografía urbana de la zona, con fuertes desniveles, que persistió hasta los años ochenta. El relleno parcial al interior de la muralla llevó a la conservación de la misma, ya que las casas de la acera de los pares de la calle Magdalena Baja-Pta. de Martos se situaron en parte sobre ella, mientras que hacia el exterior se extendían las huertas de la Ribera Alta hasta

I A.M.J.A.C. 5 de abril de 1660, citado por Ma S. Lázaro, 1988, p. 31. 
el Caño del Agua (CHAMORRO 1971:44). Las casas levantadas a partir de los años sesenta en la Carretera de Córdoba se adosaron en principio a la muralla, o la emplearon como cierre de sus corrales. Pero desde los años noventa parte de la misma ha desaparecido, eliminada por los grandes edificios que se construyen en la actualidad, que van de una calle a otra. No obstante, aún subsisten algunos tramos (CASTILLO 199I).

De las tres torres dibujadas por Wyngaerde en esta zona, una puede ser la más próxima a la Puerta, en muy mal estado de conservación. La segunda, situada en medio de la manzana, quizá sea la dibujada por A. Pérez Lendinez y publicada por A. Cazabán (1918), y señalada también por J. Eslava (1999). Y la tercera está ubicada en el extremo Este de la calle, empotrada hoy entre las casas de la zona (PÉREZ, ESTEBAN 1991). Según las investigadoras, esta presentaba en su cara Norte dos fases. La más antigua de tapial, realzada con mampostería regular, con las piedras trabadas con otras más pequeñas. No se descarta que originalmente toda la torre fuese de tapial, y que la mampostería no pase de ser una "camisa" colocada por el exterior, lo que no pudo comprobarse por haberse instalado sobre la parte superior del torreón una grúa. La muralla que se unía a la torre fue desmontada, y sustituida por un muro contemporáneo de mampostería para sostener el terreno, quizá por el mal estado que debía tener la cerca medieval.

Desde esta torre bajaba otro lienzo en dirección Norte, que termina en un torreón circular macizo, que aún se conserva en la confluencia entre la calle Molino de la Condesa y la carretera de Córdoba, y que posiblemente se corresponde con otro de los dibujados por Wyngaerde. Su estructura sugiere, por comparación con otros, que fue levantado en el siglo $X V I$. Hasta cierto punto puede vincularse a las estructuras de la Puerta del Aceituno.

El lienzo que unía la torre y el torreón mencionados aparentemente ha desaparecido por completo. En la excavación de un solar abierto a la calle Magdalena Baja, en las proximidades de la torre, no se ha localizado (ROYO
1998), por lo que debía encontrarse más al Norte, y presumiblemente fue destruido al levantar, en la segunda mitad del siglo $X X$, el Colegio Ruiz Jiménez, y abrir la calle Molino de La Condesa para dar una rápida salida al barrio desde la plaza de La Magdalena a la carretera de Córdoba.

\section{EL ANTEMURO DEL CONDESTABLE}

En el tramo situado por delante del tramo de muralla comprendido entre las puertas de Martos y el Aceituno, ambas inclusive, el Condestable hizo levantar inicialmente cinco molinos harineros, que fueron seguidos de otros hasta llegar a treinta, para abastecer de harina a la ciudad. Y así mismo reforzó las defensas:

"para guarda y defensa de los dichos molinos, mandó fazer desde las Peñuelas, baxo de la Puerta de Martos, fasta la cava que llega al adarve, una cava; do mando poner muchos mandeletes. E iva por el camino que va debaxo de las dichas peñuelas, fasta la puerta del Azeituno, otra cava bien fuerte. La qual, asi mesmo, mandó fortificar con muchos mandeletes y tapiales" (Relación... 2001:225).

$[\cdots]$

"mandó fazer una cava desde la puerta de Martos, por el camino abaxo, fasta en cabo de todas las huertas. Y dende bolvía por en canto de unas haças e de las dichas huertas un grand trecho. Y tenia en voluntad de çercar todas las dichas huertas y el exido de la puerta Barrera fasta llegar a la puerta de Noguera, a lugares de la dicha cava e a otros de valladares plantados de çarçamoras e canbroneras, que muy fuertes se podian fazer; a fin que si la dicha çibdad oviese de ser çercada otra vez, las dichas huertas e los molinos que en ellas avía mandado fazer de toda contrariedad estoviesen seguros. Pero, por los grandes trabajos e guerras que después le ocurrieron, esta obra non la pudo por entonçes acabar" (Relación... 200 I: 248).

En 1573 se afirma que el adarve o barbacana de las puertas de la ciudad contaba con saeteras y una anchura de: 
"siete a ocho Pies y obra de una lanza en alto (...) que los antiguos avian echo para guarda y amparo de la dicha puerta (...) y que estovan ansi todas las puertas de la dicha cibdad"?

\section{LA PUERTA DEL ACEITUNO}

Esta fue situada por Pi i Margall (1985: 204,n. I) en el campillejo de Cambil, por lo que en el pasado su acceso debía realizarse desde la actual calle Millán de Priego. Este error ha sido el origen de numerosas confusiones a lo largo del tiempo, ya que la Puerta se encontraba en realidad unas decenas de metros al Norte, y su acceso se realizaba desde la carretera de Córdoba.

Entre la actual calle Molino de la Condesa y la Calle Millán de Priego, existe un amplio espacio que ha sido ocupado desde el siglo XIX sucesivamente por una almazara, por parte del hospital de S. Juan de Dios, y en el último tercio del siglo $X X$ por el cuartel de bomberos, estando previsto ubicar en la zona un palacio de congresos. En ese espacio se situaba la Puerta del Aceituno [o Asetona según Wyngaerde], una de las más importantes de la ciudad por su gran complejidad, que sólo ahora, tras las excavaciones arqueológicas efectuadas, empieza a comprenderse en toda su amplitud.

Los restos aún conservados de la muralla en esta zona corresponden al torreón circular ya mencionado, del que parte el lienzo que limita el lado derecho (N-NE) de la parte baja de la calle Molino de La Condesa, y que en el punto donde hoy se interrumpe, giraba hacia el $\mathrm{N}$ atravesando el solar hasta llegar a la Calle Millán de Priego, donde giraba nuevamente hacia el Este. En el punto de giro se encontraba una poderosa torre con su frente exterior en $\mathrm{D}$, aunque en la calle Millán de Priego sólo se advierte un extraño chaflán. En ese lienzo que atraviesa el solar es donde se abría la Puerta del Aceituno. Las excavaciones en este sector muestran la extraordinaria complejidad defensiva que alcanzaron las puertas de la ciudad.

Entre el lienzo donde se encontraba la Puerta y el muro que, bordeando la carretera de Córdoba, va desde el torreón de la calle Molino de la Condesa a la torre en $D$ y que delimitó modernamente el cuartel de bomberos, hay un amplio espacio, que debía servir para el control de las mercancías y el cobro de las tasas. Ligeramente al interior del muro actual se han encontrado restos de lo que podría ser la cava -foso- abierta por el condestable, y más al interior estaría el antemuro, que a modo de barbacana cerraba el espacio, y que debió ser derribado entre los siglos XVI y XVII. Según indica M ${ }^{a}$ S. Lázaro (1988:37), en las actas Capitulares de 1586 aún se menciona la existencia de un puente para acceder a la barbacana, por lo que el foso seguía abierto.

\section{LA MURALLA DE LA CALLE MILLÁN DE PRIEGO}

La muralla seguía después el trazado de la actual calle Millán de Priego, con dirección general SE hasta alcanzar la actual Plaza de Los Jardinillos. Para este largo tramo, además de las diversas noticias incluidas en la Relación de los hechos... de Miguel Lucas de Iranzo, tenemos tres autores que aún pudieron ver $\mathrm{u}$ obtener noticias directas de las puertas existentes: Anton Van den Wyngaerde, el deán J. Martínez de Mazas y P. Madoz, todos sitúan tres puertas, pero hay algunas diferencias en los nombre señalados por cada uno:

\begin{tabular}{|c|c|c|c|}
\hline Relación.... & & Pta. de Baeza & Carnecerya \\
\hline Wyngaerde & Postygo Nova & Pta. del Sol & Carnecerya \\
\hline Deán Mazas & s Pta. del Sol & Pta. de Baeza & Sin nombre \\
\hline P. Madoz & Pta. del Sol & Pta. de Baeza & Pta. S.Agust \\
\hline
\end{tabular}

2 A.M.J.A.C. 2 de septiembre de 1573. Citado por Mª S. Lázaro 1988, p. 33. 
La discrepancia tiene al menos dos explicaciones. Una es suponer que el pintor no reseñase la de Baeza, lo que resulta en principio poco probable. La segunda es que sufriese una confusión de nombres. Si tenemos en cuenta que con respecto a la Puerta del Sol el deán Mazas indica que "hay una buena fuente", que en esa zona y época sólo puede ser la del Arrabalejo, y que Madoz indica que la misma: "hoy es un portillo"; y que ambos autores afirman que la de Baeza está "junto al colegio de Niños Huérfanos", puede concluirse que efectivamente existían tres puertas, que en época de Wyngaerde la del Sol estaría recién abierta, teniendo menos empaque que las medievales y la denominó Postygo Nova, mientras que aplicaba el nombre de la del Sol a la de Baeza.

Pasando al análisis de detalle de estos tramos hay que advertir que antes de la construcción de la muralla en la zona ya existía un importante desnivel, que la muralla no haría sino incrementar, generándose una falsa terraza. Esto explica el desnivel existente entre la calle Millán de Priego y las calles situadas hacia el interior.

En el primer tramo, entre las puertas del Aceituno y del Sol, la muralla se ubicaba detrás de las casas con números impares de la calle Millán de Priego y sirviendo de soporte a las pares que se abrían a las calles Borja, Plz. Cambil y Fernando IV. En este tramo, ni el dibujo de Wyngaerde, ni la documentación escrita mencionan la existencia de torres. Tampoco se han documentado arqueológicamente.

En la calle Borja, se localizó hacia el interior de la ciudad y separada varios metros de la muralla medieval, restos de la muralla romana (ZAFRA 1992).

Ya hemos indicado que, con frecuencia, siguiendo a Pi i Margall, se ha ubicado a la altura de la Plaza de Cambil una puerta, identificada con la del Aceituno. Aclarada la auténti- ca situación de esta última, en dicho lugar quizá hubiese un Postigo, aunque ya hemos señalado que no creemos que sea el Postygo Nova que señala Wyngaerde. No hay que olvidar que al menos desde el siglo $X V$ se registra la frecuente apertura de postigos en la muralla, muchas veces ilegales, efectuados por los vecinos para acceder más fácilmente a sus propiedades, o para introducir productos en la ciudad eludiendo los impuestos ${ }^{3}$. Estos postigos serían igualmente tapiados frecuentemente por las autoridades, sobre todo en momentos de peligro, no sólo por la guerra, sino también frente a las epidemias. En las excavaciones efectuadas en la zona no se ha encontrado ningún elemento que pueda confirmar o desechar la existencia de ese portillo en concreto.

Desde los años sesenta han venido levantándose en la zona edificios con fachadas a las dos calles, lo que explica la desaparición de la muralla medieval en algunos de esos puntos (PUERTA et alii 1998). No obstante, las excavaciones recientes en un edificio del siglo XIX en el $N^{\circ} 59$ de la calle (ARIAS et alii 2004), ha proporcionado la mejor imagen hasta el momento de la estructura de doble muralla y foso que caracterizaba las defensas de la ciudad de Jaén.

La Puerta o Portillo del Sol, posiblemente sea un acceso construido en el siglo $X V I$, que debía encontrarse al final de la calle Fernando IV. De la misma hasta ahora no se han encontrado restos.

La gran manzana que ocupa el espacio entre las calles Fernando IV y la Plaza de Los Huérfanos — donde se encontraba la Puerta de Baeza- estaba separada de la calle Millán de Priego por la muralla, como pudo comprobarse en las excavaciones efectuadas (CASTILLO et alii 1991). Aunque esta fue casi completamente destruida antes de la excavación, y no se intervino al exterior de la misma para comprobar si tenía antemuro y foso, sí pudo estudiarse la complejidad del lienzo principal, con

3 Así lo recogen por ejemplo Ma S. Lázaro 1988: 45-46 y C. Diez Bedmar 2002: 107 I y doc. I3।I. 
sucesivos cuerpos adosados, incluyendo un pequeño torreón hacia el exterior, muy tardío, que es posible que tuviese una función de contrafuerte del lienzo, más que defensivo. Tampoco en este tramo Wyngaerden refleja torre alguna, lo que confirmaría su escasa relevancia.

Aunque en época islámica en la zona existieron casas, la mayoría del espacio interior de esta manzana estuvo ocupado desde la conquista castellana por instalaciones industriales. Quizá hubo aquí inicialmente unas tenerías de las que tanto abundaron entre los siglos XIV y $X V I$; a partir del siglo XVI hubo un molino harinero (XIMENEZ PATON 1628), que sería sustituido después por las instalaciones de la aceitera, que han subsistido hasta finales del siglo XX. Hace años apareció un arco en la confluencia de la calle San Andrés con la Plaza de Los Huérfanos, que J. Ureña (1986) sugirió relacionar con la Puerta de Baeza, lo que las excavaciones han descartado. Por su parte Mª S. Lázaro (1988:36) señaló que podría ser la puerta que, según las Actas Capitulares de 1699, se hizo "en lo bajo de la calle San Andrés que es por donde todos se mandan". Posiblemente se trataba de una gran puerta de acceso a la calle de ronda de la muralla y al molino harinero; posteriormente la calle de ronda sería incluida en las instalaciones de la aceitera, y la puerta daría acceso a las mismas.

\section{LA PUERTA DE BAEZA}

Tanto el deán Martínez de Mazas, como P. Madoz, ubican esta puerta en la plaza de los Huérfanos, hoy Blanco Nájera. Con respecto a la misma la Relación de los hechos... (200 I, p. II7, 123, 142, 368) la menciona, pero no describe ningún elemento de la misma. Algo más se indica en la documentación estudiada por $\mathrm{M}^{\mathrm{a}} \mathrm{S}$. Lázaro(1988:36), según la cual en las actas Capitulares de 1695, en relación con la demolición de un lienzo de muralla anejo a ella, se especifica que sus arcos eran de ladrillo, fuertes y que había "una torre que miraba a la puerta Vaeza mas de seis varas fuera del arco". Y finalmente el deán Mazas, dice que: "son dos puertas en una dispuestas de modo que ninguna se descubre de frente", pasaje que $M^{a}$ S. Lázaro interpretó como la referencia a una estructura en codo. La puer- ta ya no existía en época de Madoz. Las excavaciones actuales (NAVARRO et alii 2004), permiten comprender mejor esas explicaciones.

Entre la Puerta de Baeza y la de las Carnicerías, Anton Van den Wyngaerde sitúa cuatro grandes torreones, en un lienzo que en el siglo XX seguía por la manzana de casas situada entre Millán de Priego y la calle de Las Huertas. Uno de ellos debe ser el que menciona $\mathrm{S}$. Lázaro (1988: 80) como destruido en 1732. Otro fue descubierto hacia 1977 frente a la calle Castilla, con ocasión del derribo de la casa $n^{\circ}$ I I de la calle Millán de Priego, y que fue rápidamente demolido, y al que hacen referencia varios autores, pero que sepamos sólo describe J. Eslava (1999a:58-60):

"[...] aparecieron un torreón y un fragmento de lienzo de muro de I I'60 metros, todo ello de tapial".

"El torreón macizo hasta una altura de 7 metros estaba desmochado de antiguo por lo que nos fue posible conocer su altura original ni si estaba provisto de cámara superior. En su costado norte, pegada a la muralla, y a una altura de poco más de un metro, se abría una galería de poco más de 1.50 metros de altura, con bóveda de ladrillo puesto de canto, que profundizaba unos tres metros horizontalmente en el interior del torreón y luego parecía continuar hacia arriba en forma de pozo, pero esta parte, rellena de tierra, no era ya practicable. Había señales de utilización moderna de esta galería que daba al patio interior de la referida casa número once, pero su origen parecía contemporáneo a la construcción del muro. ¿Se trataba de una poterna?".

“El torreón media 4'30 de fachada y 3'60 de lado. Sus encofrados tenían unos 80 centímetros al igual que los de la muralla. Los más bajos, hasta unos tres metros de altura, eran de tapial de calicanto fortísimo, muy rico en cal y grandes cantos rodados en la mezcla. Los superiores eran de calicanto mucho más modesto, casi tapial de tierra con escasa proporción de cal. Lo que quizá explica la deficiente conservación del remate de esta obra. En la muralla había restos de muro de mampuesto aprovechado por la estructura de tapial. Tenía un grosor de 1.60 
metros y una altura de 9 metros que debiera corresponder aproximadamente a la original puesto que, por la parte intramuros, la altura era de poco más de cuatro metros (medida por la calle de Las Huertas)."

En un texto anterior, y en otros aspectos menos completo, el mismo autor (CEREZO, ESLAVA 1989:14;1999b:17) al hablar de este torreón y muralla agregaba que:

"Delante del muro principal había otro secundario a antemuro y delante de este una cava o foso que, según una fuente del siglo XIII era muy honda."

Aunque posiblemente ese elemento no era realmente visible, y los textos en cuestión, claramente orientados a la divulgación, trataban sólo de dar una imagen de cómo sería el conjunto fortificado de la ciudad, recurriendo a la información de las crónicas a las que ya nos hemos referido.

Excavaciones recientes en solares abiertos a la calle Millán de Priego han documentado en algún caso la existencia de la muralla al fondo de los mismos, sirviendo de medianería con las casas abiertas a la calle de Las Huertas (MORILLAS 1997; KAYSER y otros 1999), aunque en otros ya había sido derribada posiblemente entre finales del siglo XIX y principios del $X X$.

Al final de la actual calle Huertas, la muralla torcía hacia el Suroeste, subiendo ligeramente por la actual plaza de S. Agustín, que en el siglo XIX era la parte baja de la calle Arroyo de S. Pedro, según cabe deducir de la nota que incluye Pi i Margall ( 885 p. 203-204, n. I). Dicho autor menciona un Portillo del Arroyo de S. Pedro, con arco ojival, mención que recoge F. Rábago (1915) aunque ya había desaparecido en su época.

\section{LA PUERTA DE LAS CARNICERÍAS Y EL TORREÓN DE S. AGUSTÍN}

El nombre de Puerta de las Carnicerías procede de la proximidad a la misma de una de las carnicerías de la ciudad, por lo que debió recibirlo en el siglo XIV o quizá ya en el XV; la mención más antigua conservada se encuentra en la Relación de los hechos... (200l, p. 101 102), precisamente cuando se habla del intento de traslado de todas las carnicerías de la ciudad y de la construcción de un matadero junto a la Puerta Barrera:

"[...] por cuanto las carneçerias de la dicha çibdad están dentro en ella, en diversos lugares no convenientes, do los vezinos de aquellas comarcas reçibian grande perjuicio del olor de las carnes e de las sangres podridas, de que se seguían otros inconvenientes, por aquello evitar y por enobleçer la dicha çibdad, mandó començar e labrar de cal y canto, desde un postigo que está fuera de la puerta que dizen de las Carneçerias, el adarve adelante del Arraval, fasta en par de un pilar que está çerca de la puerta Barrera para fazer alli una carneçceria francesa. E mandava façer lugar apartado do matasen las carnes e echasen la sangre, poque las carneçerias estoviesen gentiles e limpias. E allí tenía ordenado que estoviesen todas juntas."

El fracaso del traslado, que la misma Relación... reconoce, hizo que la puerta siguiera conociéndose por la de las Carneçerías durante mucho tiempo. Así aparece en el grabado de Wyngaerde de 1567, y en los documentos aportados por $M^{a}$ S. Lázaro (1986:36): en 1604 , en el pleito sostenido entre el convento de Santa María de los Angeles y el convento de San Agustín se especifica que este último está construido "frontero de los adarves de la puerta Carnezeria", y nuevamente en I621, cuando se menciona entre los bienes del Cabildo "la torre de la puerta Carnicería junto a Santo Agustín". Pese a la temprana instalación de los agustinos junto a la puerta, esta no tomará su nombre hasta mucho después, tal vez cuando las carnicerías desaparezcan de la zona.

Por lo que se refiere a la puerta en sí, las noticias son muy escasas. $M^{a} \mathrm{~S}$. Lázaro recoge que en las Actas Capitulares del586 se indica que "la entrada de la puerta Carniceria que haze callejón y vuelta donde no ay casa ninguna", lo que interpreta como que era una puerta en codo. Pero este tipo de grandes puertas suelen consistir en una torre de gran tamaño, en el interior de la cual se desarrolla el acceso, con 
las entradas situadas en dos caras no enfrentadas de la torre. $O$ en todo caso, si existen dos torres, ambas estaban unidas por un pasillo, generalmente cubierto en todo o parte del recorrido, como sucede en el castillo de La Iruela (Jaén). Ninguna de estas situaciones parece darse en el caso que estudiamos.

Los datos aportados por las excavaciones de las puertas de Martos y Baeza, donde se utilizan expresiones semejantes, indican en efecto que el significado no era exactamente ese, sino que alude al hecho de que las torres no estaban en el mismo plano, sino que una se adelantaba a la otra, lo que unido al corte del terreno situado por delante, generaba aparentemente una "revuelta". Este corte del terreno se evidencia también en el hecho, observado por JC. Castillo, de que las puertas estaban situadas a cierta altura en relación al exterior de las mismas, por lo que el acceso era bastante complicado. Pese a los cambios sufridos por la topografía urbana, esa diferencia de altura aún es particularmente apreciable en los casos de la Plaza de Los Huérfanos en relación con la calle Millán de Priego, y en el del área donde se ubicaba la Puerta de Granada.

En relación con esto, JC. Castillo también ha advertido que los conocidos "cantones" que han caracterizado hasta ahora la ciudad de Jaén, y que están siendo eliminados por las actuales reformas de las plazas, se sitúan precisamente en las proximidades de las puertas. Para este especialista, es posible que los mismos fueran construidos con la finalidad de sostener rampas que facilitasen el acceso a las puertas. Los cantones, las rampas, más las dos torres no alineadas, crean efectivamente accesos complejos, compuestos por vueltas y callejones, pero no eran lo que se denomina puerta en codo.

Volviendo a la Puerta de las Carnicerías, un elemento que también resulta significativo de la misma, es el hecho de que según el dibujo de Anton Van den Wyngaerde, las torres que enmarcaban esta puerta se distinguían de todas las demás por presentar planta poligonal. Este dibujo coincide con el testimonio de Pi i Margall, que en 1885 indicaba que la muralla "continuaba probablemente hacia el campillo de San
Antonio, donde existen todavía dos altos torreones octógonos..." de forma que aunque la puerta ya hubiese desaparecido, sí existirían las dos torres que la enmarcaron. Esto es lo que permite situar esta puerta en las manzanas delante de la plaza actual de Los Jardinillos, de forma genérica entre las calles Ruiz Romero y la actual Plaza de San Agustín.

El problema es que a parte del dibujo, la referencia de Pi i Margall es la única que habla de dos torreones en esta zona. Todas las demás noticias, de cronistas o de documentos de archivo, hablan de un sólo torreón, hasta el punto de que Soledad Lázaro consideró que la referencia de $\mathrm{Pi}$ i Margall probablemente era un error (LÁZARO 1988:31), mientras que J. Eslava (1999a: 65; 1999b: 14) sugiere la posibilidad de que podría haber sido una torre albarrana.

Aunque el dibujo de Wyngaerde y la noticia de Pi i Margall se refuerzan mutuamente, y por ello son casi con toda seguridad correctas, creemos preciso analizar todas las demás informaciones para poder integrarlas en la descripción. Se trata de establecer si todas se refieren al mismo torreón o si de ellas puede deducirse que existían dos. Y porqué la mayoría de las noticias sólo mencionan uno.

La primera noticia es de las Actas Capitulares del 16 de enero de 1587, recogida por Ma S. Lázaro (1988: 44) que indica que la torre contaba con una sala interior a la que se accedía desde el adarve, y que estaba dedicada a cárcel. Noticia que amplia L.M. Sánchez (1997: 66-68) quien agrega que esta función la cumpliría de forma intermitente, y para la que:

"La Ciudad cometió y encargó a Alonso Palomino Quesada, regidor, que haga aderezar la Torre de la Puerta Carnicería para que sirva de cárcel, atento a la necesidad que de ellos tiene esta ciudad. Y para ello se libraron diez ducados."

A una torre diferente parece hacer alusión la mención contenida en el Catastro del Marqués de la Ensenada, según noticia recogida también por L.M. Sánchez (1997:67), que hace alusión tanto a la torre como a la barbacana que habría delante de la misma: 
"Es también de dicha fortaleza [del castillo] la torre que dicen de San Agustín por estar cerca de dicho convento. Se compone de un cuarto bajo que sirve de cuartel, otro alto que sirve de prisión y su plaza de armas. Tiene de diámetro once varas y veintitres de alta. Su figura ochavada...".

La discrepancia entre las descripciones del siglo XVI donde sólo se menciona una planta, y la del siglo XVIII donde son dos, intentó resolverla L.M. Sánchez (1997:67) sugiriendo que ello quizá se debía a que "en ese intervalo de tiempo se hubiera despedregado y habilitado la planta baja".

Otros textos anteriores a Pi i Margall, se refieren también a un sólo torreón, aunque sólo proporcionan una descripción general de su planta, lo que no aporta nada. Es el caso del deán Martínez de Mazas (P. 44), que sólo menciona la Torre Ochavada de San Agustín, o de Pascual Madoz, que en 1847 dice "[...] es un polígono de planta de bastante elevación, todo de piedra en buen estado, no obstante los daños que le hicieron los franceses en su primera invasión y cuando quemaron dicho conv. que esta á su espalda" (p. 148).

Algo semejante sucede con la descripción que se hace en el expediente ${ }^{4}$ realizado en 1886 para la demolición de la torre, recogido por Ma S. Lázaro (1988:44), el torreón era "un octógono irregular [...] conteniendo sus lados o contornos treinta y ocho metros longitudinales y la torre catorce con sesenta y nueve centímetros de elevación".

Por otro lado, el expediente ubica esta torre en el Campillo de San Antonio (Plaza de Los Jardinillos), contiguo al $N^{\circ} 12$ de la calle Magdalena del Prado, es decir, en la zona donde Pi i Margall vió dos torreones. Aunque precisando más su situación.

Además, en ese expediente sí hay una curiosa anomalía, y es el hecho de que frente a los nombres tradicionales de Carnicería o de San Agustín, la denomina Torre del Condestable, cambio que quizá implique que había dos torreones (el de San Agustín y el del Condestable), aunque con el tiempo hasta los nombres acabaron confundiéndose.

A ello podemos agregar el hecho de que en realidad sí hay otro autor que menciona un segundo torreón en las inmediaciones, aunque no lo describe. Se trata de P. Madoz, que indica que:

"próximo a esta torre [la de S. Agustín] hay otro torreón que en el día está dentro de una casa particular, y desde allí sigue la muralla metida en las casas y sube por la calle Tiradores...".

Ma S. Lázaro propuso identificar este torreón con el que apareció frente a la calle Castilla, pero del texto no puede deducirse eso. Parece claro que existía en el interior de una casa _ irelacionada en algún momento con alguno de los condestables que residieron en Jaén y de ahí el nombre?-- en cualquier caso, esa aparente "privatización" del torreón y su escasa visibilidad, explicarían que no aparezca recogido en la documentación del concejo.

La documentación es tan fragmentada y confusa que efectivamente lo más razonable era llegar a la conclusión de que había un único torreón. Pero el dibujo de Wyngaerde sumado a la noticia de Pi i Margall despejan todas las dudas, y posibilitan una relectura de los documentos, y entonces sí aparecen indicios de había dos torres. En consecuencia, la puerta de Las Carnecerías o de San Agustín estaba formada por dos grandes torreones ochavados con cámara superior y, al menos uno de ellos, con otra inferior, presumiblemente para el cuerpo de guardia. Se denominaron respectivamente de S. Agustín y del Condestable. Y la puerta se encontraba situada entre las calles Tiradores (o Ruiz Romero) y Magdalena de Prado.

\footnotetext{
4 A.M.J. Leg 429 Expediente para el derribo de la torre sita en la plazuela de San Antonio que forma parte de la antigua muralla de esta población.
} 


\section{LA MURALLA DESDE LA PUERTA DE LAS CARNICERÍAS AL PORTILLO DE SAN BARTOLOMÉ}

A partir de la Puerta de San Agustín el dibujo de Wyngaerde no sirve para aclarar los elementos que componían la muralla, ya que el autor al realizar una panorámica frontal, lo que hace es representar el lienzo exterior que abrazaba el barrio de S. Ildefonso, de forma que desde la Puerta de San Agustín traza un lienzo hasta la Puerta Barrera. Alguna de las imágenes que dibuja en profundidad podrían corresponder a torreones, pero con muchas dudas, y sin poder ubicarlos con seguridad.

Pero ese mismo dibujo parece implicar que el quiebro hacia el Oeste se hacía en la propia puerta. Se han formulado diversas hipótesis acerca de por donde subía la muralla, pero hasta que la arqueología no aporte datos en contrario, conviene ceñirse a las indicaciones de P. Madoz, que son las más antiguas y concretas. Volviendo al párrafo que acabamos de citar:

"próximo a esta torre [la de S. Agustín] hay otro torreón que en el día está dentro de una casa particular, y desde allí sigue la muralla metida en las casas y sube por la calle Tiradores, Campillejo de las Cruces y se une a la pared posterior de la cárcel...".

Como hemos indicado la calle Tiradores es la actual Ruiz Romero, y el Campillejo de las Cruces ocupaba la parte de la actual calle Dr. Eduardo Arroyo que se extiende desde el cruce de la calle Álamos con la calle Colón hasta el comienzo de la propia calle Ruiz Romero.

En las excavaciones efectuadas en un solar en la parte alta de la calle Ruiz Romero, en el lado de los pares (Norte), apareció una gran fosa vertedero fechada aparentemente en época almohade. A parte de fauna y cerámica contenía abundantes rollos de horno, lo que según la autora de la intervención sugiere la presencia de alfares en las proximidades (LLORENTE 1998). Ello a su vez implicaría que la zona estaba al exterior de la muralla, y que esta estaría desplazada hacia la calle Magdalena del Prado. Pero ello choca no sólo con la afirmación de P. Madoz, sino también con el desarrollo que la zona muestra en el plano de detalle efectuado al abrir el tramo de la actual calle Dr. Eduardo Arroyo en 1968 entre las calles Tiradores y Magdalena de Prado. Dicho plano muestra que allí había varias casas de gran tamaño (con patio central, jardín, etc.) y varias de ellas bastante antiguas, que se fechan entre los siglos XV y XIX, lo que descarta la existencia de la muralla en ese segmento. En consecuencia, la muralla habría debido ir más bien por la acera de los impares de Tiradores, e incluso desplazada hacia la calle Salido.

Según noticias orales, la muralla sí se conserva aún hoy en la parte posterior del $N^{\circ} 5$ de la calle Dr. Eduardo Arroyo (al menos en la sastrería allí ubicada), que se sitúa frente a la manzana que separa las calles Ruiz Romero y Salido, lo que confirmaría lo anterior. Ese espacio corresponde al antiguo Campillejo de las Cruces. Esto implica que casi contra la muralla debe apoyarse la Iglesia — antes mezquitade San Bartolomé. No sorprende por tanto que en ese lienzo se abriera en 1553, según las Actas capitulares, el portillo de S. Bartolomé ${ }^{5}$, aunque el mismo no ha sido ubicado con precisión.

La muralla seguiría luego por la calle Murallas y la actual Plaza Cervantes, prolongándose en el primer tramo entre las calles Cerón y Álamos, que corresponde a la anchura de la actual calle Colón. En esa zona se encontraba la cárcel a que alude Madoz. Esta cárcel se había construido adosada a la muralla entre 1538 y 1543 con accesos desde plaza de La Audiencia. Según J.L. Sánchez (1997:86-95) fue la primera Cárcel Real con que contó Jaén; en base al plano conservado y a las descripciones,

5 Citado por Mª S. Lázaro, 1988:98 
parece que la muralla se horadó para ubicar en su interior y a lo largo de la misma las celdas, ocupando la última de ellas un torreón, que quedaría aproximadamente a la altura de la confluencia actual entre las calles Colón y Álamos, que aún en 1835 es descrito como torre baluarte, que debía proteger un pequeño quiebro de la muralla. Cuando la cárcel se traslade y sus restos se derriben, contra la muralla se apoyarán la casa y las cocheras que la sucedieron, según cabe deducir del plano realizado para la apertura de la calle Colón, lo que ocurrirá entre 1860 y 1889 (OÑATE 1998).

Al comienzo de la actual calle Cerón se ha detectado un Portillo (BELLÓN y otros 1996). Quizá se trate del Portillo de S. Francisco, abierto en I 546 a petición de los frailes del convento homónimo, y que comunicaba el arrabal de S. Ildefonso, o quizá más exactamente los terrenos del propio convento, con el interior del recinto principal. Aunque en ocasiones se ha supuesto que este portillo estaría ubicado a la altura de la actual Plaza Cervantes (CHIQUERO et alii 1990) la construcción ahí de la cárcel antes citada parecen descartarlo. En cualquier caso en el siglo XIX ya habría sido tapiado por innecesario.

Después, la muralla seguía entre las actuales calles Cerón y Los Alamos, habiendo sido localizada en algunos puntos (BARBA, CALDERÓN 1999), siendo posible que se conserve algún torreón entre las casas, hasta llegar a la Puerta de Santa María.

\section{LA PUERTA DE SANTA MARÍA}

Debía estar situada aproximadamente hacia la mitad de la actual calle Campanas y en parte en el espacio ocupado hoy por el Sagrario. La zona ha sufrido abundantes transformaciones a lo largo de los siglos, debido a que la Catedral creció constantemente en esta dirección. Entre el siglo XIII y mediados del XVI la puerta tenía una disposición en codo, y por delante de la misma se extendería una amplia barbacana, similar a la de la Pta. del Aceituno, y que al igual que aquella además de reforzar la capacidad defensiva de la misma, debía de servir para el control de mercancías.
Hacia I 463 el Condestable Miguel Lucas de Iranzo afirma que fortaleció la puerta, pero la noticia no aclara en que consistió la obra:

"[...] fizo reparar e fortificar las torres de la puerta de Santa María, do la puerta se fizo mas fuerte. E en las dichas torres se fizo una carçel muy buena para tener los presos [...]."

El crecimiento de la Catedral a partir del primer tercio del siglo XVI, hizo que el obispado considerase esta Puerta como un obstáculo, realizando constantes intentos para su demolición, pese a la oposición inicial del Concejo y del propio rey Carlos I. Sin embargo, progresivamente las obras la irían cercenando hasta hacerla desaparecer, proceso que, como recogió detalladamente $M^{a}$ S. Lázaro (1988), puede seguirse a través de las Actas Capitulares y de la documentación del Archivo Diocesano.

El primer documento es una Real Provisión de Carlos I, que debe ser ligeramente anterior a 1530, aunque se conoce por las referencias al mismo contenidas en las Actas Capitulares correspondientes a la sesión del Cabildo de 2 de septiembre del573:

"[...] la tha puerta que era la mas fuerte y suntuosa que abia en todo nuestro reino del andalucia y que en la tha puerta estavan tres torres muy altas y fuertes y almenadas [...] que haziendo una puerta como querian hazer enfrente de otra que no tenia tanta fortaleza como en tenella a un lado adonde agóra diz que la tiene e enfrente de cada puerta hecho su adarve para defensa y amparo y para mas fortaleza como ella estava que parecia cosa ympunable...".

En 1555 se vuelve a mencionar la puerta en el Memorial de la torre del Alcotón [A.D.J.], donde se hace referencia a la torre cuyos:

"linderos y sitio pareze el mismo donde esta el sagrario viejo y lo que dicen arcos y cimenterios de que usa y arrienda la fabrica...".

En 1634 [según recogen las Actas Capitulares] el cardenal Sandoval solicita de la Ciudad "media torre de la puerta Santa María" para la construcción de algunas de las capillas laterales. 
En 1659, el Cabildo Eclesiástico solicita permiso para derribar el resto de la puerta, y despejar así el espacio lateral de la Catedral. Las Actas Capitulares recogen un informe de los alarifes en el que se subraya el estado ruinoso de las torres, existiendo una "media torre" adosada a la catedral "aterraplenada" mientras que la otra, aunque conservaba su primitiva planta, el parecer de los alarifes, incidía en su derribo parcial "por estar carcomida por los temporales y amenazando ruina". Además, según ellos, el derribo de las torres redundará "en el servicio del comun por quitarse las revueltas y quedar toda la calle derecha". Se derribará efectivamente en 1660 la media torre adosada al Sagrario y el arco de la Puerta, mientras que la torre frontera sobrevivió algún tiempo.

En base a esos textos se han sugerido diversas disposiciones de las torres, aunque sigue faltando un estudio minucioso del área. Sobre todo, porque en el siglo transcurrido entre la Carta de Carlos I y el último informe, las torres han pasado de ser tres a dos, sin que haya una explicación convincente.

Por lo que se refiere a las torres, hay acuerdo general en que se trataba de torres cuadradas con cámaras, aunque no está claro cuantas. Mª Soledad Lázaro (1 988: 43 y 35-36) no encuentra datos para poder pronunciarse:

"Las torres de la Puerta de Santa María obedecen a un tipo de planta cuadrada, con salas interiores, saeteras y almenas como defensa de la puerta a la cual flanquean."

"Tanto la puerta como las torres disponían de diferentes cámaras utilizadas como tiendas por los comerciantes que las arrendaban. En la parte baja, en el callejón y recodo, se localizaban asimismo varias tiendas al igual que la "capilla del santo $\times p 0^{\prime \prime} 6$.

Por su parte L.M. Sánchez Tostado (1997: 48-49) enumera diferentes posibilidades, tenien- do en cuenta el uso de cárcel que le dio el Condestable Iranzo a al menos una de las torres:

"[...] se tiene ciertas dudas sobre si formaban una única dependencia en la parte superior, siendo macizas en su mitad inferior, lo que le otorgaría una mayor consistencia defensiva, con una única dependencia en su parte superior y un acceso mediante escalera adosada a la terraza almenada; o si, por el contrario, poseían dos plantas. Encontramos frecuente el primer tipo siendo un ejemplo la Torre de las Damas que defiende la puerta del castillo de Jaén o el Torreón del Conde de Torralba que aún se conserva en la Carrera de Jesús".

"En cambio también cabe la posibilidad de que ambas torres contuvieran dos plantas de acceso bajo a través del adarve y comunicadas por medio de una escalera adosada a su interior. Así parece por la documentación obrante en la Cuenta de Propios del Archivo Histórico Municipal de Jaén [...]".

Pero lo más probable es que estemos ante torres de planta cuadrada, macizas hasta el adarve, cada una con una sola dependencia en su parte alta, comunicadas entre sí por encima de la puerta, y cada una con acceso independiente a su propia terraza almenada. Estructura defensiva que puede apoyarse en los siguientes puntos:

I. La mayoría de las torres defensivas de la muralla presenta su planta baja maciza para evitar su acceso mediante perforación. Por ello parece ilógico que, tratándose de una puerta de vital importancia en el acceso a la ciudad, muy próxima a puntos neurálgicos de culto y gobierno, fuera de las pocas que mantuvieran dos plantas.

2. La documentación [citada por Ma S. Lázaro] del Archivo de Propios describe su arriendo a comerciantes. Con la expresión "en la parte baja..." se puede interpretar tanto que existían cámaras inferiores, como

6 A.M.J. Cuentas de Propios. 
suponer que la expresión se refiere al pasillo en recodo en el que, al parecer con el tiempo, se ubicaron tiendas.

Por lo que se refiere al espacio delante de la puerta, estaría ocupado por una potente barbacana protegida por el antemuro, barbacana que describe una real Provisión de Carlos I, según la cual tenía de "siete a ocho pies en ancho y obra de una lanza en alto". Y en las actas Capitulares de 1575 se indica que la cerca tenía "dos vueltas de muralla y rebellon y antemuro por el qual tiene sus saeteras".

No obstante la barbacana en cuanto espacio defensivo debió caer en desuso durante el siglo $\mathrm{XV}$, al construirse la muralla del arrabal de S. Ildefonso, y en ella se construyeron las carnicerías, que debieron entorpecer de forma notable el paso por la puerta, de forma que el Condestable Iranzo hacia 1463:

"[...] mandó desfazer e quitar unas carneçerias que estavan en saliendo por la puerta de Santa María de la dicha çibdad; mandolo todo allanar e linpiar, poque estavan muy mal e ocupavan la entrada e salida. E mandolas fazer a la mano izquierda de la dicha puerta, pegado a la barbacana del adarve, muy muncho mejor que no estavan. Por manera que en saliendo agora por la dicha puerta, pareçe luego toda la plaça del Arraval" (Relación..., 2001: p.101).

\section{LA MURALLA EN LA CATEDRAL Y EL AYUNTAMIENTO}

Desde la Puerta de Santa María la muralla atravesaba el espacio hoy ocupado por el Sagrario de la catedral. En el lado sur de la misma se encontraba la torre del Alcotón, de la que existe un amplio documento, gracias a los intentos de los obispos por derribarla para ampliar la catedral. Dicha información ha sido sistematizada por Ma S. Lázaro ( 1988:40-4I) cuyo completo comentario reproducimos:
"Responde al tipo de torre poligonal, ochavada, al igual que el torreón de San Agustín y curiosamente nunca se ha reparado en ella. El célebre Memorial de la torre del Alcotón, elaborado en 1554 con el fin de proceder a su demolición para ampliar la catedral por el sur, ha sido el único expediente que nos ha permitido establecer una serie de puntos sobre su traza y configuración. Este informe proporciona noticias detalladas e interesantes para nuestro estudio, insertándose en él las opiniones al respecto de Andrés de Vandelvira, Francisco de Escalona, Alonso Barba, Francisco del Castillo padre y Francisco Rodríguez, todos ellos ligados de una manera u otra a esta torre, bien por su participación en la obra nueva de la catedral, como fue el caso de Vandelvira, Alonso Barba y posiblemente Francisco Rodríguez o bien a través de sus intervenciones en diferentes obras municipales como es el caso de Francisco de Escalona y Francisco del Castillo, fiel alarife y albañil de la Ciudad el primero y arquitecto municipal el segundo, al menos así se revela por su participación en diferentes obras públicas, depósitos de agua, fuentes, edificios de tipo funcional como carnicerías y alhóndigas e incluso calles."

Del conjunto de las opiniones de los diferentes maestros cabe deducir los siguientes puntos:

- Su situación en el ángulo sureste de la catedral y por lo tanto muy cerca del ángulo que hacía la muralla al torcer en dirección a la calle Carrera de Jesús hacia el sur. El memorial menciona la existencia, asimismo, de "dos torres, una del cabo de arriba y otra del cabo de abajo que hazen cuerpo algunas deltas con la yglesia" ". Ello demuestra que la cerca no bajaba en su origen hasta la puerta Noguera sino que seguía un trazado lógico rodeando la catedral, reforzándose el ángulo formado con una de las torres mencionadas por Escalona. Al margen de élla, existe otra referencia que señala la presencia de un "posti-

7 A.D.J. Memoria de la Torre del Alcotón. Parecer de Franciasco de Escalona.

8 Ibid. Parecer de Andrés de Vandelvira. 
go viejo de la obra de la tha yglesia mayor que sale de cara del arcediano de Úbeda a la parte del mediodía" 8 el cual era utilizado por los vecinos del arrabal para entrar en la ciudad, según la opinión de Vandelvira, pasando por lo tanto a ella a través de la iglesia.

- De su situación, adosada a la catedral no hay duda. Escalona afirma que "por la parte de la tha yglesia esta un arco envestido en ella" información que Francisco del Castillo completa diciendo que "la tha torre esta fundada a la parte de la tha yglesia mayor sobre dos arcos que responden con la yglesia los quales están cerrados". Realmente serían los muros de la catedral los que apoyarían directamente sobre la torre, obedeciendo dichos arcos a posibles accesos al interior de la torre, cegados.

- El estado de ruina de la torre. "... la torre es vieja y tiene dos hendiduras desde arriba abaxo e parece que tiene mal fundamento porque por la parte de la tha yglesia esta un arco envestido en ella adonde agora esta sacristia y vestuario y es obra vieja e muy antigua e de muy flacos materiales y es torre sin defensa parques cerrada y no tiene troneras ni ventanas y es ciega que no se puede servir por ella artilleria alguna". De la opinión del alarife se desprende que no estaba realizado en piedra refiriéndose con "esos flacos materiales" posiblemente a cajones de tapial. En dicha época debía estar desmochada y semidestruida con el acceso a una posible cámara superior cegado tanto en los adarves como desde el pie de ella, hemos de hacer notar que no se menciona que sea maciza "sino que es ciega".

La muralla se dirigía con cierta inclinación en dirección Oeste-Suroeste hasta llegar al actual Ayuntamiento. Sobre ella y aprovechando las torres existentes se construyó el primer edificio del Concejo municipal, probablemente en la primera mitad del siglo XVI (MARTíNEZ DE MAZAS 1978:193-194), que aprovechó al menos una torre (LÁZARO 1988:80).
El trazado oblicuo de la muralla dificultó el cierre del lateral Sur de la Catedral, ya que para completar el trazado regular era imprescindible el derribo de toda la muralla de la zona y naturalmente del edificio del propio Concejo. Esto le enfrentó constantemente con los sucesivos obispos y jerarcas eclesiásticos, ante los que fue cediendo progresivamente. En 1555 Carlos $V$ cedió a la iglesia la torre del Alcotón y el segmento de muralla más próximo; después, en I590, el cabildo Municipal cedió otro tramo de la muralla y parte de las casas consistoriales para la construcción de la torre Sur de la Catedral. Y finalmente en 1758 se derribo el tramo que había quedado adosado a dicha torre y que llegaba hasta la altura del actual Ayuntamiento, tramo perforado por el Postigo de las Cadenas, que daba acceso desde la plaza al Juego de Pelota, hoy Carrera de Jesús (MARTÍNEZ DE MAZAS 1978:197-198). Lo que fue posible por el previo traslado del Ayuntamiento al Palacio de los condes de Garcíez, luego duques de Montemar, levantado en el siglo XVI, y ubicado donde hoy está el palacio municipal, que sustituyó a aquel en el siglo XIX.

\section{LA MURALLA EN LA CARRERA DE JESÚS}

La cerca seguía luego por la manzana situada entre las calles Carrera de Jesús (llamada en I 898 Jesús Montilla y antes del Juego de Pelota) y Obispo González (antes callejón del Toro).

En el primer tramo, que corresponde a la manzana donde se ubica el actual ayuntamiento, Ma S. Lázaro (1988:32 y 80) señala la presencia en él de un torreón de planta cuadrada.

Entre esta manzana y la siguiente se habría el Portillo de San Sebastián (según Wyngaerde) o Arco de San Sebastián (MARTíNEZ DE MAZAS 1978:44), actualmente calle del Arco de Los Dolores, abierto en el siglo XVI ${ }^{9}$. Estaba flanqueado por dos grandes torreones cilíndricos macizos, uno de los cuales subsiste en

9 A.M.J.A.C. 1554 (citado por Mª S, Lázaro 1988:80). 
el lado Suroeste de la calle, incorporado a la vivienda existente en la esquina, y que fue restaurado hace unos años.

De ese torreón parte el siguiente tramo de la muralla. Esta se conservó por la vicisitudes de la zona. En conjunto, por delante de gran parte de la muralla se ubicaron las antiguas cocheras de los bomberos, y se creó una plaza sobre la mismas, quedando la muralla al fondo, aunque tapada por casas de escasa calidad. En la actualidad podemos dividir este tramo en tres sectores. La visión del primer sector ha sido recuperada en lo últimos años (MARTíN, MARTíN 2004), incluyendo un torreón circular, macizo, de 3.50 metros. Parte del siguiente fragmento, desaparecido en altura, se localizó en excavación frente a la plaza de Cruz Rueda (PÉREZ 1993). El último fragmento se ha conservado dentro del Colegio Público Sto. Tomás, y finaliza en un gran torreón de planta cuadrada, que igualmente ha sido restaurado (BERGES 1973 y 1986):

“El torreón (...) pertenece al tipo de adarve cubierto, el cual corre a lo largo de su planta baja, abriéndose en ambos extremos dos arcos apuntados de ladrillo y dispuestos en otros tantos parámetros opuestos entre sí. Desde el adarve cubierto se pasa al interior de la sala baja del torreón, que se cubre con una bóveda de horno, ejecutada en ladrillo. Tres saeteras iluminan este recinto. Una escalera dispuesta en el interior del muro permite el acceso a la azotea, donde se restauró la lucana de salida, así como el peto de coronación de la misma" (BERGES 1973:52).

A este triple fragmento de muralla es al que deben hacer alusión las actas capitulares cuando señalan en 1626 que la muralla bordeaba los jardines de D. Antonio de Córdoba y Mendoza ${ }^{10}$, y en 1630 que se conceden a D. Yñigo de Córdoba y Mendoza "...los guecos de las tres torres que alindan con la muralla y también con sus casas principales la tha muralla que está frente del convento de carmelitas descalzas" "I. Y al menos el gran torreón cuadrado siguió vinculado a la misma propiedad, dentro del palacio del conde de Torralba, nombre con el que se le sigue conociendo.

Por último cabe señalar que la estructura de la manzana actual hacia el Oeste a partir del torreón, sólo se habría formado si la muralla seguía una línea ligeramente oblicua durante al menos 10 ó 20 metros.

\section{LA TORRE "SARNOSA"}

$M^{a}$ S. Lázaro concedió gran importancia a esta torre (1988:39), que sin embargo no aparece mencionada por la mayoría de los autores del siglo XIX. Por el interés e implicaciones de sus sugerencias nos parece necesario comentar el párrafo que le dedica:

"La torre Sarnosa aparece ya mencionada en las Actas de Cabildo ${ }^{12}$ de 1476 como torre en la que se disponía un cuerpo de guardia y vigilancia siendo la primera de las enumeradas de sur a norte. El hecho de que se disponga en ella un turno de guardia demuestra que era torre principal y fuerte. La documentación que hemos manejado la sitúa en el ángulo que forma la muralla al torcer desde la puerta de Granada hacia la calle Carrera de Jesús. Cazabán (1930a) y más recientemente L. Berges (1973) mencionan la existencia de una torre, precisamente en este mismo lugar. En realidad corresponde al esquema de torre-cubo de planta cuadrada, ya que así la mencionan las escrituras de arrendamiento del Cabildo y las Actas Capitulares, situada en un ángulo de la cerca, contribuyendo a una defensa más activa tanto del lienzo que se sitúa junto a ella, como de la puerta que se abría a su lado. Presenta salas o cámaras que se arriendan a particulares lo que en algunas ocasiones hace que

\footnotetext{
10 A.M.J.A.C. de 5 de marzo de 1626 (citado por Mª S. Lázaro (1988:32).

1 I A.M.J.A.C. 1630 (citado por Mª S. Lázaro, 1988:32).

12 A.M.J.A.C. 1476, Rodriguez Molina Colección...
} 
se la denomine la "casa-cubo". Debió flanquear a la mencionada puerta de Granada y el patio intermedio de el acceso de esta, puesto que en otras ocasiones es denominada torre-corral." 13

Es decir, Ma S. Lázaro sugiere que la Torre Sarnosa era él mismo Torreón del Conde de Torralba. Y parece apuntar la posibilidad de que pudiera ser una de las que flanqueaban la Puerta de Granada.

Con respecto a lo primero, ciertamente con ello se completaría bastante la historia de este torreón, que a partir del siglo XVII quedaría integrado en el palacio de los Córdoba y Mendoza, luego condes de Torralba. Sin embargo, hay algunas objeciones: a) si efectivamente hubiese formado parte de la Puerta, o estado en las proximidades de la misma, no habría habido espacio para el desarrollo en profundidad del palacio; b) esa relación se habría reflejado en las escrituras de autorización de uso concedida a la familia Córdoba y Mendoza; c) ya hemos comentado que por la estructura de la manzana en la que se encuentra el torreón del Conde de Torralba, el lienzo que partía del mismo debía tener una inclinación oblicua, la existencia de un quiebro en ángulo recto en ese punto, como parece que se producía en la torre "Sarnosa", habría cerrado la manzana en el mismo lugar; d) posiblemente la Puerta de Granada estaba situada en la actual calle del Conde, casi en la confluencia con la actual calle Arco de la Puerta de Granada, con lo que la distancia entre ella y el torreón del conde de Torralba era demasiado grande. Por tanto, creemos que la torre "Sarnosa", era distinta del Torreón del Conde de Torralba, aunque sí pudo ser una de las que flanqueaban la Puerta de Granada.

\section{LA PUERTA DE GRANADA}

Excavaciones recientes permiten formular la hipótesis de que parte de la Puerta de Granada estuviese en el $N^{\circ} 8$ del callejón del Conde, próximo a la esquina con la calle Arco
Puerta de Granada. En la entrada del edificio se han colocado grandes sillares, aunque ello no recuerda la estructura existente. Mencionada en la Relación de los hechos... (2001, pp. 109, 142, 308). Por las fuentes escritas sólo se sabe que tenía arco de herradura, y como las demás del recinto estaría flanqueada por torres. La arqueología ha aportado algún dato más, aunque escaso.

\section{MURALLA SURESTE}

Denominamos así a los lienzos que desde la Puerta de Granada llegan al extremo del alcázar castellano. En la actualidad puede considerarse dividida en dos tramos, separados por la Carretera de Circunvalación del Castillo.

\section{De la Puerta de Granada a la Carretera de Circunvalación}

Desde la Puerta de Granada la muralla se dirigía en dirección al alcázar, subiendo por la calle Horno de la Pta. de Granada, o mejor dicho entre las casas con fachada a esta y los huertos del Convento de La Merced, donde aún se conservan parte de los lienzos y al menos dos torres (CASTILLO 1994a y b), hasta alcanzar la actual carretera de circunvalación. El tramo finaliza en una torre rectangular, cuyos restos son visibles junto a la carretera, revestida de argamasa (CHIQUERO, MORENO 1990).

\section{De la Carretera de Circunvalación al Castillo}

El tramo, sumamente quebrado y aprovechando la roca, tiene, $470 \mathrm{~m}$. "lineales", pero sólo I 45 construidos. Levantado directamente sobre la roca, salva un pronunciado desnivel. Presentan cuatro torres, que posiblemente tenían más una función de contrafuertes que de defensa, y un postigo. Parte del lienzo y las torres son en realidad obra reciente, "restauración" destinada a recuperar la imagen, pero de escaso interés.

13 A.M.J. Cuentas de Propios. 


\section{MURALLA SUR-SUROESTE}

Por la parte Sur y Suroeste la ciudad estaba protegida por el fuerte cortado en cuya cima se encontraban los alcázares, por lo que en época medieval no parece que hubiera defensas especiales. Sin embargo, en el siglo $\mathrm{XV}$ las Relaciones de los hechos... informan de una serie de obras que formaron parte del que hemos denominado Antemuro del Condestable:

"[...] Y fuera de la dicha çibdad, en el camino que sale de los dichos alcáçeres fazia las torrecillas por do viene el agua de la fuente al caño a do lavan las mugeres que estavan en los alcáçeres Viejo e de Abehuy e davan agua a las bestias de los dichos alcáçares, mandó fazer otra cava muy buena."

"E desde la dicha cava, el camino abaxo que viene de las dichas torrezillas que va a la puerta de Granada, fasta llegar a las peñas que están en par de la torre mayor del castillo de Abehuy, mandolo tapiar de dos tapias en alto; e en par de la dicha cava y las tapias por do venia la dicha agua, mandó tapiar e fazer una casa tejada bien larga, de nueve tijeras en luengo, con dos puertas: la una contra el dicho castillo de Abehuy y la otra contra la sierra."

\section{LA MURALLA \\ DEL ARRABAL DE LAS MONJAS}

Este es un recinto conocido sobre todo por haber sido devastado durante la incursión nazarí de 1368. En 1542 se realizaron arreglos en el muro con mampostería. Al conjunto se refieren como adarve y barbacana respectivamente las Actas Capitulares en I 542 y 1586 (LÁZARO 1988:80). Esta zona estaba dedicada a huertas, entre las que destacaban las que poseían las monjas de Sta. Clara. Aunque tradicionalmente se ha supuesto que el primer convento de las mismas, antes del ataque nazarí, se encon- traba en este lugar, parece más probable que estuviese desde el principio en el interior de la ciudad (SALVATIERRA 2003).

Según S. Lázaro, comprendía las calles A. Noguera, Llana (hoy $\mathrm{F}^{\circ}$ Coello) y Abades. Es decir, el trazado arrancaría de la Torre del Alcotón con dirección Este, habiéndose "fosilizado" en el nombre de la calle: Almenas. Giraría luego hacia el Sur alejándose de la catedral, por la actual calle Manuel Jontoya hasta la Puerta Noguera, que comunicaría el arrabal con el exterior, giraría hacia el Oeste y subiría por la calle Abades. La comunicación con la ciudad era complicada, ya que sería necesario salir de la ciudad por la Puerta de Santa María, y entrar en el arrabal por la de Noguera. Para solucionarlo, en el año I500 la ciudad obtiene autorización real para abrir un portillo en la mura$\| a^{14}$. Al mismo parece referirse $\mathrm{F}^{\circ}$ de Escalona al hablar de un "postigo viejo de la obra de la tha. yglesia mayor que sale de cara del arcediano de Ubeda a la parte del mediodia" (LÁZARO 1988:40).

Esta propuesta de S. Lázaro presenta varios problemas: además de que este trazado genera una superficie muy reducida, el principal problema es la contradicción que supone el mismo con el papel que la puerta Noguera jugó en el último cuarto del siglo $\mathrm{XV}$.

Hay que tener en cuenta que por ella salía frecuentemente el Condestable Iranzo para sus cabalgadas y alardes (Relación... pp. 141, 243, 247), y que por ella entró en la ciudad en 1469 el rey Enrique IV (Relación... p. 324), época en la que según los propios documentos aportados por S. Lázaro aún no existía comunicación entre el arrabal y la ciudad.

En realidad, el trazado descrito por esta autora parece que se deduce de la descripción del recinto que hace P. Madoz (1988: I 48), cuya información en este aspecto era bastante deficiente.

14 A.M.J.A.C. 1500, fols.94v-95r recogido por J. Rodriguez Molina, 1985 doc. LXXXVII. 
Una hipótesis alternativa, es que la muralla -que partiría efectivamente de la Torre del Alcotón-, lo haría con ligera dirección Sur, saldría por la calle Abades, donde existían restos de la misma (CHAMORRO 1973) ${ }^{15}$ y donde estaría el Portillo de acceso al arrabal, cuya presencia ha quedado registrado en la calle del mismo nombre. Giraría luego hacia el Oeste, recorriendo la calle Llana, englobando parte de las calles paralelas a la de Abades (Julio Angel, etc.). La muralla quizá llegaría a enlazar nuevamente con la muralla principal en las inmediaciones de la Pta. de Granada, o en algún punto indeterminado de ese trazado. En este caso, el muro sí protegería efectivamente las extensas huertas que se desarrollaron en esa ladera del Barranco de los Escuderos, y sería efectivamente una barbacana o antemuro de la muralla. La fortificación se componía exclusivamente de un muro, quizá una tapia, sin torres ni otros sistemas de defensa.

\section{LA MURALLA DE S. ILDELFONSO}

El arrabal o barrio de S. Ildefonso fue la principal zona de expansión de la ciudad entre los siglos XV y XIX. La muralla de S. Ildefonso era de menor envergadura que la islámica, tenía menos elementos defensivos, influyó menos en la evolución de la ciudad, etc. motivos por los que ha despertado siempre menos interés entre los historiadores, con las lógicas excepciones (LÁZARO 1988:82). Esta muralla partía probablemente de la Torre del Condestable, en la Puerta de las Carnicerías, con dirección Este. Ha sido localizada en excavación en el № 2 del Paseo de la Estación (GÓMEZ DE TORO 1989). Bajaría por la actual calle Correa Weglison hasta su encuentro con las calles Virgen de la Capilla y Av. De Madrid, donde se encontraría la Puerta Barrera, principal entrada del barrio durante mucho tiempo. En el dibujo de Anton Van den Wyngaerde, la puer- ta tenía una sola torre cuadrada, que según el dibujo parece que tenía cámara superior. Debe ser la misma a la que ya en estado ruinoso hace referencia una noticia ${ }^{16}$ de 1729.

Diversas noticias permiten ubicar algunas torres a partir de este punto, que veremos en su momento. Sin embargo, sólo conocemos por su nombre las torres del Cabo y la del Molindooro, aunque sin que se conozca su ubicación (LÁZARO 1988:82).

A continuación de la puerta, Wyngaerde dibuja un largo lienzo hasta otra torre, que por el sombreado de la misma y la muralla, posiblemente estaba en un quiebro de la cerca. Ese debe ser el tramo que desde la Puerta Barrera bajaba por la calle Peso de la Harina hasta el Portillo de San Jerónimo, posiblemente construido en el siglo XVI para dar facilitar los movimientos del convento homónimo, sustituido en 1575 por el de los capuchinos, y estos desplazados a su vez entre 1616 y 1618 por el de la Concepción Franciscana (La Bernardas), gran edificio que supuso el derribo de las murallas y de una torre (GALERA 1985:218).

A partir de la torre, en el dibujo de Wyngaerde parece existir un doble muro, o una muralla con barbacana, que aparentemente finaliza en una poderosa estructura almenada. La perspectiva, hace imposible identificar de que elementos se trata. Ese sector debe ser el que corresponde en parte al convento de $\mathrm{S}$. Jerónimo.

En esa zona, al otro lado del Convento, se abrió en 1586 la Puerta Nueva, que quizá es la misma que algo después aparece con el nombre de S. Rafael. Y que fue sustituida en los años cuarenta del siglo XVII por la de S. Miguel Arcangel, conocida actualmente como Puerta del Angel, junto al convento de Franciscanas descalzas o Bernardas (GALERA 1985:65).

\footnotetext{
I5 Si tenemos en cuenta que todo el testero de la Catedral es una obra posterior al derribo de la torre, queda claro que el nombre de la calle Almenas no tiene nada que ver con el posible recuerdo de este trazado.

16 Citada por Mª S. Lázaro 1988:82.
} 
Desde la última puerta, la muralla se dirigía nuevamente hacia la Catedral, formando el lado Sur del arrabal. En el primer tramo de este lienzo estaría La Coracha. Una coracha era, en época islámica, un pasillo fortificado, entre dos murallas, que permitía atravesar una zona sin protección entre dos puntos de interés. Buenos ejemplos de coracha son la que une el castillo de Gibralfaro con la Alcazaba en Málaga, o la alcazaba Cadima de Granada con el río Darro.

La referencias a la coracha de Jaén se refieren generalmente a casas ubicadas en una calle que llevó ese nombre ${ }^{17}$. M. López Pérez indica que La Coracha de Jaén estaba en la parte baja de la calle Azulejos, dice que era "Una fortificación consistente en un adarve derivado de la muralla principal que finalizaba en una torre que albergaba un pozo, lo que permitía hacer la aguada sin peligro en caso de asedio" (LÓPEZ PÉREZ 2003:71). Puesto que esa es una de las definiciones de coracha que suelen utilizarse, no queda claro si dicho autor lo cita en términos generales, o si se refiere a elementos realmente existentes que no documenta. En el último caso, si tenemos en cuenta que la calle Azulejos estaba completamente dentro de la muralla, habrá que concluir que los mencionados torre y pozo estaban en la zona de los actuales jardines del hípico. Sobre ese conjunto no hay noticias en las fuentes más antiguas. Forzando al límite la hipótesis, no habría que descartar que esa torre fuese la que dibuja Anton Van de Wyngaerde, de un tamaño que contrasta notablemente con todas las demás, a pesar de que en teoría estaba más lejos que muchas de ellas. En cualquier caso no conocemos noticias sobre ninguna otra torre al exterior de la ciudad.

Existiera o no coracha, la muralla subía a continuación en dirección Oeste. Sólo interrumpida por el Postigo Don Diego, abierto en 1542, que posiblemente se relacionaba de alguna forma con la fuente Don Diego, abastecida a través del raudal de Sta. María. Y finalmente enlazaría con la antigua muralla del Arrabal de Las Monjas.
En la confluencia, se construiría la Puerta o Arco Noguera de la que ya hemos hablado. Estaba situada al extremo de la actual calle Manuel Jontoya, en el cruce con las calles Llana y Juan Izquierdo. Aunque no se conservan descripciones antiguas de la Puerta, esta parece haber consistido en un doble arco apuntado, al que se le agregó un portillo lateral peatonal. Desde el siglo XVIII ha tenido una peculiar historia de desaparición y recuperación (LÓPEZ 2003).

\section{FUENTES}

Hemos incluido en este apartado todos los textos de autores que aún pudieron ver directamente la muralla, así como aquellos más recientes que por el volumen de documentación de archivo inédita que incluyen, cabe emplearlos igualmente como tales.

Ciudades del Siglo de Oro. Las vistas españolas de Anton Van den Wyngaerde. (Ed. Richard L. Kagan) Barcelona 1986.

Crónica de la población de Ávila. Ed. Amparo Hernández. Valencia 1966.

Colección diplomática del Archivo Histórico Municipal de Jaén. Siglos XIV y XV. Jaén 1985. Ed. José Rodríguez Molina

Lázaro Damas, Ma S. (1988): Desarrollo histórico del casco urbano de Jaén hasta 1600. Jaén.

Madoz, Pascual (1845-1850): Diccionario geográfico estadístico histórico de España y sus posesiones de Ultramar. Madrid. (Ed. Facsimil Jaén, Jaén 1988).

Martínez de Mazas, J. (1794): Retrato al natural de la ciudad y término de Jaén. (Ed. Facsimil Barcelona 1978).

Pi i Margalll, Francisco (I 885): España, sus monumentos y arte. Su naturaleza e historia. Jaén, Málaga, Granada y Almería. Barcelona.

Relación de los hechos del muy magnífico e mas virtuoso señor, el señor Don Miguel Lucas muy digno Condestable de Castilla. Ed. Juan Cuevas, Juan del Arco y José del Arco. Jaén 200I.

Ximenez Paton, B. (1628): Historia de la antigua y continuada nobleza de la ciudad de Jaén. Jaén. (Ed. Facsimil Jaén 1983). 17 Como por ejemplo Ma S. Lázaro (1988:32) en la escritura de arrendamiento de una casa en l65I (A.H.P.J. Leg. |4|4, fo 27) sin ubi-
cación concreta. O Eloisa Ramirez, en el Catastro de Ensenada, con datos para identificar la calle con la actual Azulejos. 


\section{BIBLIOGRAFÍA}

Aunque las excavaciones arqueológicas son indudablemente fuentes, al ser los informes necesariamente producto de la interpretación de los datos, los hemos considerado como bibliografía y no como fuentes directas.

Arias, F'; Alcalá, Fa; Barba, V.; Navarro, M. (2004): El foso defensivo del sistema de fortificación de la ciudad medieval de Jaén. Excavación arqueológica en el solar de la calle Millán de Priego n 59. Arqueología y Territorio Medieval II.2

Barba, V.; Calderón, J.A. (1999): Informe de la intervención arqueológica de urgencia en la calle Cerón $N^{\circ} 23$ esquina con la calle Parra, de Jaén. (Informe inédito). Jaén

Barba, V.; Alcalá, Fa; Arias, Fo; Navarro, M; Herranz, A.B.(2004): "Nuevos datos para el estudio del sistema de fortificación medieval de la ciudad de Jaén. Intervención arqueológica en la Puerta de Martos" Arqueología y Territorio Medieval, vol. I1.2.

Bellón; JP.; Barba, V,; Lisalde, R.; Alcalá, F. (1996): Informe preliminar sobre la intervención arqueológica de urgencia en el solar sito en la calle Cerón números 17 y 20 de Jaén. (Informe inédito)

Berges Roldán, Luis (1973): "Restauración del torreón llamado del Conde de Torralba del recinto medieval de la ciudad de Jaén" Castillos de España № 12 (segunda época); diciembre; Madrid pp. 52-53;

Berges, L. (1986). "Un tramo de la muralla sur de Jaén". Senda de los huertos, 7, Jaén pp. 55-66.

Castillo Armenteros, JC (199|): Informe arqueológico del solar sito en la Carretera de Córdoba Nº 33 de Jaén. (Informe inédito, Jaén)

Castillo Armenteros, JC (1994a): "Excavación arqueológica de apoyo a la restauración en la iglesia de La Merced de Jaén". Anuario Arqueológico de Andalucía 1994, Vol. III, Sevilla pp. 242-249.

Castillo Armenteros, JC (1994b): "Informe técnico sobre los restos arqueológicos del solar sito en la calle Horno Puerta de Granada de Jaén". Anuario Arqueológico de Andalucía 1994, Sevilla vol. III, pp. 254-258.

Castillo Armenteros; JL.; Pérez Martínez, Mª C.; Marín, Ma del M.; Zafra, J. (|99|): "Intervención arqueológica de urgencia en el solar sito entre las calles Millán de Priego, Hornos Franco, Rey Don Pedro y San Andrés". Anuario Arqueológico de Andalucía 1991 Sevilla pp. 396-406.

Castillo, JL.; Cano, J. (1994): Diagnosis arqueológica de la Muralla Norte de Jaén. (Inédito).

Cazabán, A. (1930a): "La Puerta de Martos de Jaén". Don Lope de Sosa, N 207; Jaén III , pp 70-72.

Cazabán, A. (1930b): "El torreón del Conde de Torralba". Don Lope de Sosa. N²1I, Jaén, VII 1930, p. 210.

Cerezo, F.; Eslava. J. (1989): Castillos y Atalayas del reino de Jaén. Jaén.
Chamorro, J. (1971): Guía artística y monumental de la ciudad de Jaén. Jaén.

Chamorro. J. (1973): "Las murallas de Jaén". Castillos de España, $N^{\circ}$ 12, (segunda época), Madrid pp. 50-5।.

Chiquero, E.; Moreno, E (1990): Ficha técnica del conjunto defensivo de la ciudad de Jaén. (Inédito).

Díez Bedmar, C. (2002): Urbanismo y sociedad en el Jaén bajomedieval. Jaén. (inédita).

Eslava, J. (1999a): Castillos y Atalayas del reino de Jaén. Granada.

Eslava, J. (1999b): Los castillos de Jaén. Granada.

Galera, P. (1985): Catálogo monumental de la ciudad de Jaén y su término. Jaén

Gómez de Toro, E. (1989): "Informe sobre la actuación de urgencia realizada en el Paseo de la Estación Nº 2 (Muralla del siglo XVI)". Anuario Arqueológico de Andalucía Vol. III, pp. 304-306.

Jiménez Morillas, Y. (1997): Intervención arqueológica de urgencia en el solar $N^{\circ} 7$ de la calle Millán de Priego (Informe inédito. Jaén)

Llorente, M. (1998): Excavación en el solar Ruiz Romero 14. (Informe inédito. Jaén)

López Pérez, M (2003): El viejo Jaén. Jaén.

Kayser, A.; Crespo, A.; Castillo, L. (1999): Informe sobre la intervención arqueológica de urgencia en la calle Millán de Priego No 3. Jaén (Informe inédito).

Martín, Fo; Martín, B. (2004): "Caracterización de materiales e intervención sobre un tramo de muralla Sur de Jaén". Arqueología y Territorio Medieval, I I. I, Jaén.

Navarro, M; Barba, V.; Alcalá, Fa; Alcalá, Fa; Arias, Fo:(2004) "Intervención arqueológica en la Puerta de Baeza. Nuevas aportaciones del sistema fortificado de la ciudad medieval de Jaén". Arqueología y Territorio Medieval I I.2

Pérez Martínez, Ma C. (1993): Intervención arqueológica de urgencia en el solar No 2 de la Plaza Cruz Rueda (Jaén). (Informe inédito. Jaén)

Pérez Martínez, Mª C. y Esteban, A. (|99|): "Excavación arqueológica de urgencia en el solar sito en Magdalena Baja entre los números 6-4 (Jaén)". Anuario Arqueológico de Andalucía 1991, Sevilla pp. 392-395.

Puerta Torralba, D.; Lizcano, R.; Burgos, A.; Pérez, C. (1998): Informe técnico preliminar sobre la excavación arqueológica de urgencia en la cale Millán de Priego 69 (Jaén). (Informe inédito, Jaén).

Oñate, Pilar (1998): Informe de la intervención arqueológica en Cl Colón e/v Cl Cerón (informe inédito, Jaén).

Royo, Ma Angeles (1998): Informe de intervención arqueológica de urgencia en el solar situado en la calle Magdalena Baja, $N^{\circ} 2$ (antes Nº 6) de Jaén. (Informe inédito. Jaén). 
Salvatierra, V. (2003): "La judería de Jaén. Introducción a su análisis urbano". Boletín del Instituto de Estudio Giennenses, Vol. CLXXXV, pp. 42I-458.

Sánchez Tostado, JL (1997): Historia de las prisiones en la provincia de Jaén. 500 años de confinamientos, presidios, cárceles y mazmorras. Jaén.
Ulierte, L. de (1990): Jaén. La ciudad y su historia. Granada. Ureña Castro, J. (1986): "Aparición de restos de construcción de la antigüa muralla de Jaén". Senda de los Huertos, vol. 2; Jaén, pp. 33-34.

Zafra. Joaquín (1993): Intervención arqueológica de urgencia en la C/ Borja N 6 (Informe inédito. Jaén).

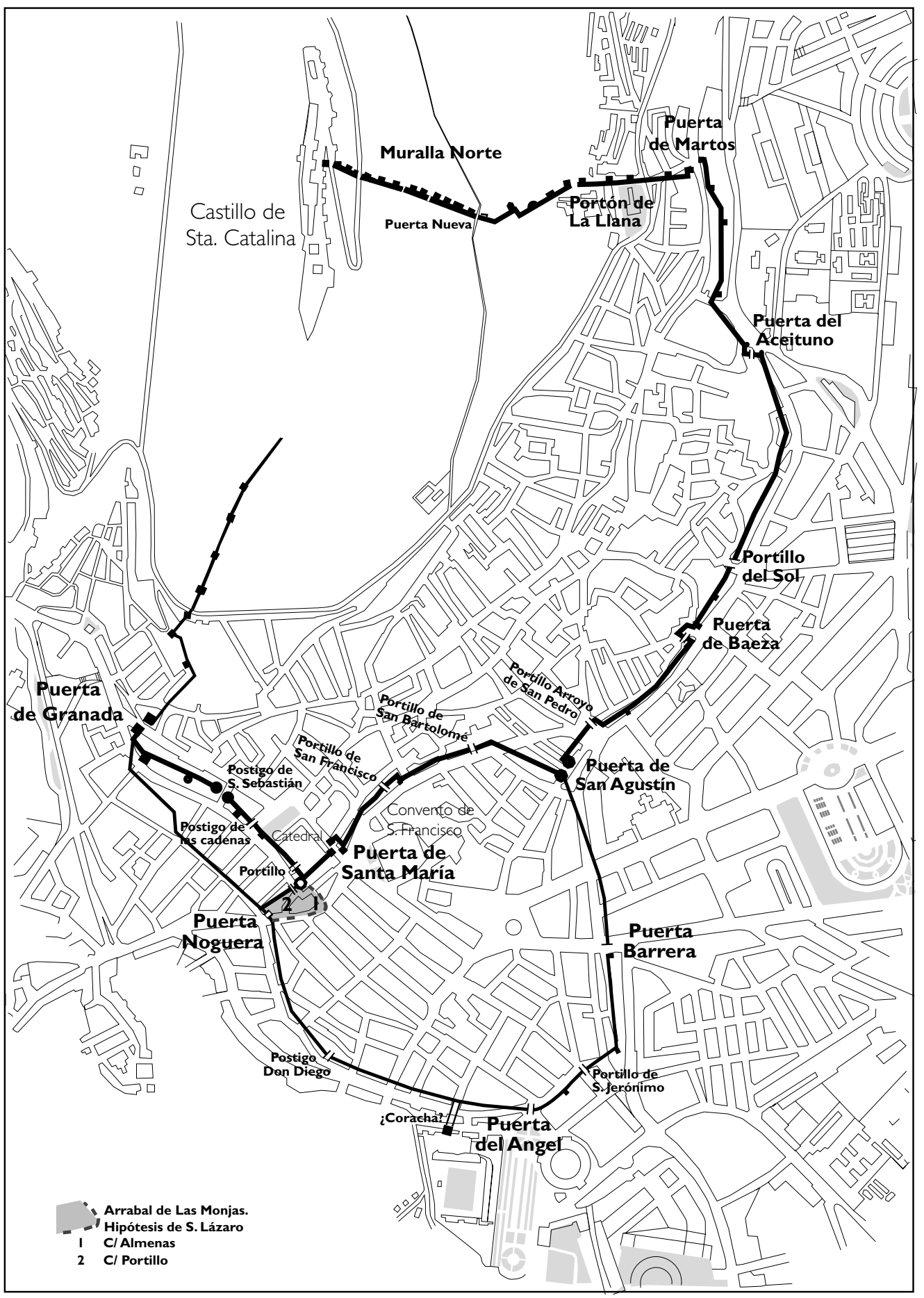

Figura I. Trazado de la muralla sobre la ciudad moderna. 


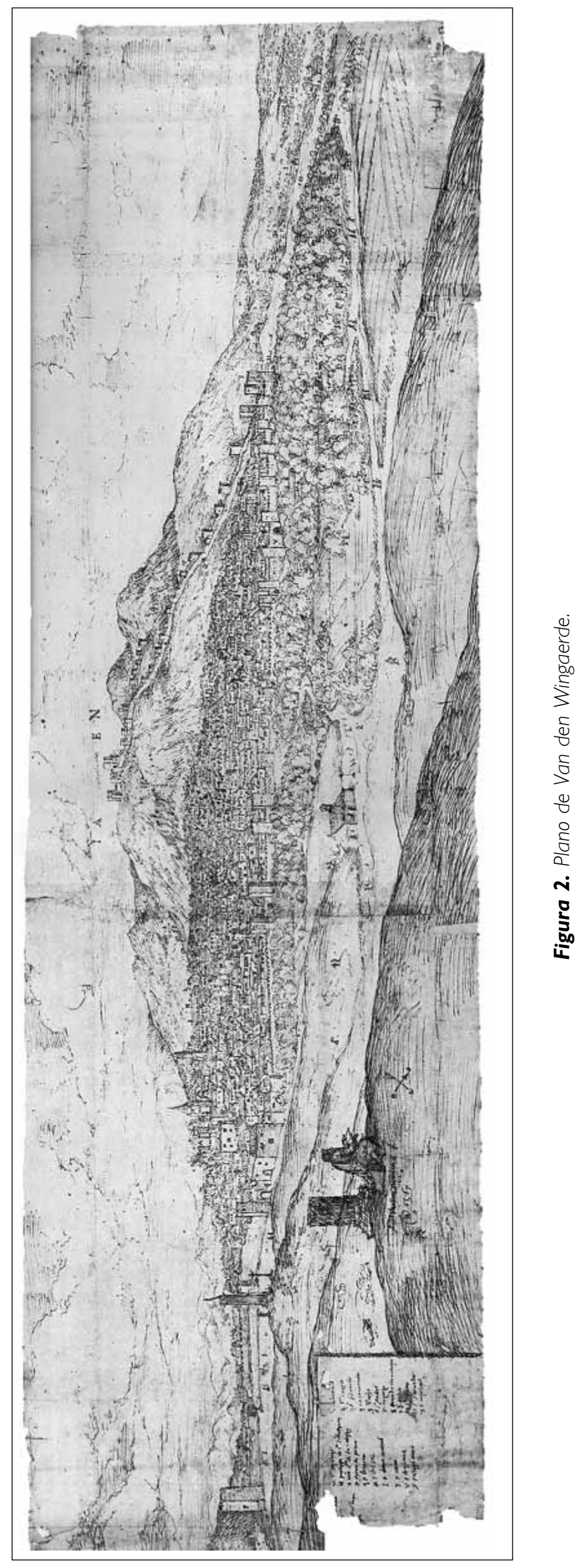

